\title{
Electromagnetic Compatibility Considerations for International Space Station Payload Developers
}

\author{
Matthew McCollum \\ NASA \\ George C. Marshall Space Flight \\ Center \\ Huntsville, Al 35812 \\ matt.mccollum@nasa.gov
}

\author{
Larry Kim \\ Jacobs Space Exploration Group \\ George C. Marshall Space Flight \\ Center \\ Huntsville, Al 35812 \\ larrykim@nasa.gov
}

\author{
Christopher Lowe \\ Jacobs Space Exploration Group \\ George C. Marshall Space Flight \\ Center \\ Huntsville, Al 35812 \\ christopher.l.lowe@nasa.gov
}

\begin{abstract}
The International Space Station (ISS) is a laboratory for scientific research, innovative technology development, and global education. The ISS provides a number of facilities and platforms for payload developers and investigators to conduct biological, microgravity, and Earth and space observation science, as well as for performing technology development. Due to the unique nature of the ISS vehicle and its electrical power and data systems, achieving electromagnetic compatibility (EMC) with the vehicle requires special considerations by the payload developer.
\end{abstract}

The ISS electromagnetic interference (EMI) requirements and test methods are based on MIL-STD-461, "Electromagnetic Emissions and Susceptibility Requirements for the Control of Electromagnetic Interference", Revision C, and MIL-STD-462, "Electromagnetic Interference Characteristics, Measurement of," respectively. The low source impedance of the test setup requires special considerations when designing or selecting EMI power filters and switched mode power supplies. Many filters, suited for later revisions of MIL-STD-461, will result in noncompliant designs. ISS electrical power system power quality requirements, imposed to protect the stability of the system, can also affect EMI filter design.

The selection and use of commercial-off-the-shelf (COTS) equipment for ISS applications requires special considerations to meet both EMC and crew safety requirements. Furthermore, the ISS environment can provide unique immunity challenges; if the payload developer ignores these challenges, the result is a possible loss of science or impact to technology demonstration.

The ISS provides a unique opportunity for the science and technology development community. However, in order to be successful, the payload developer must incorporate special EMC considerations, many of which will be presented.

\section{TABLE OF CONTENTS}

1. INTRODUCTION 1

2. ISS FACILITIES AND ACCOMMODATIONS............... 1

3. ISS REQUIREMENTS........................................... 2

4. PAYLOAD REQUIREMENTS .................................. 3

5. DESIGN CONSIDERATIONS ......................................... 3

6. PoWer Filter DeSIGN ............................................ 3

7. POWER SUPPLY SELECTION ......................................5

U.S. Government work not protected by U.S. copyright
8. GROUNDING/ISOLATION............................................6

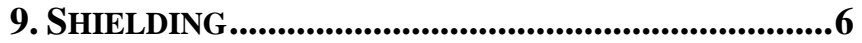

10. DATA BUS CONSIDERATIONS ...................................7

11. BONDING......................................................................

12. SAFETY CONSIDERATIONS .................................8

13. SUMMARY ............................................................8

REFERENCES ........................................................8

BIOGRAPHY ...................................................................9

\section{INTRODUCTION}

The ISS is a laboratory for scientific research, innovative technology development, and global education. The ISS is fully assembled and continuously inhabited by all space agency partners; the National Aeronautics and Space Administration (NASA), the Canadian Space Agency (CSA), the European Space Agency (ESA), Japan Aerospace Exploration Agency (JAXA), and Roscosmos State Corporation for Space Activities (Roscosmos). Weighing in at just under 1 million pounds, the ISS has a pressurized volume of more than 32,000 cubic feet and a power generation capability of greater than 75 kilowatts of power. In addition to the internal facilities, there are external locations to facilitate payloads as well.

\section{ISS FACILITIES AND ACCOMMODATIONS}

The ISS provides a number of facilities and platforms for payload developers and principle investigators to conduct biological, microgravity, and Earth and space observation science, as well as for performing technology development. These facilities can provide payloads with electrical, data, video, cooling, waste gas exhaust and vacuum venting accommodations. Two areas where these facilities reside are inside the habitable volume of the ISS, Internal Facilities, and those that are open to the space environment, External Facilities.

One of the primary means of accommodating scientific hardware in habitable volume of the ISS is Expedite the Processing of Experiments to the Space Station (EXPRESS) 
Racks. EXPRESS Racks are the most flexible modular research facility available on the ISS, and are used by NASA, JAXA, and ESA investigators. Each EXPRESS Rack provides a structural interface, power, data, cooling, water and other items needed to operate science experiments on the

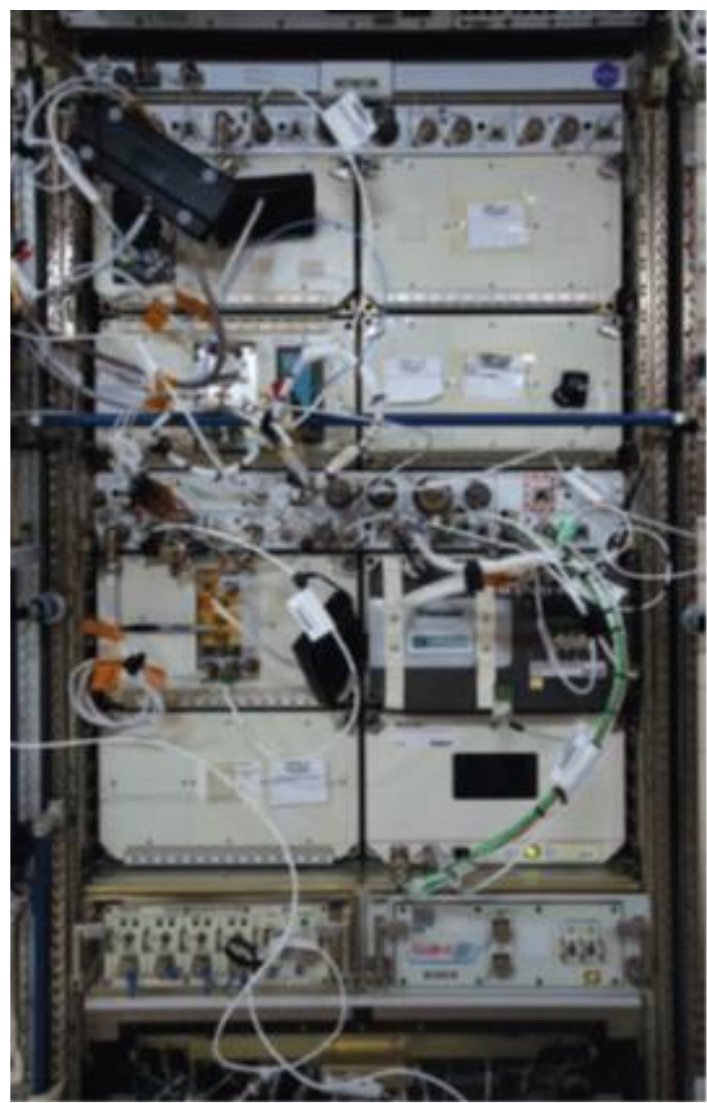

Figure 1. EXPRESS Rack 4

ISS. Express Racks support both long-term investigations as well as payload on orbit change out.

Gloveboxes provide containment for experiments, ensuring that small particles or hazardous material are confined and do not float about the cabin. The Microgravity Science Glovebox (MSG) facility, jointly developed by ESA and NASA, supports the field of material science, biology and biotechnology, fluid science, combustion science and crystal growth research while the Life Science Glovebox (LSG) provides sealed work area for life science and biological experiments.

The ISS has multiple external payload platforms. The Columbus External Payload Facility is located on starboard end of ESA's Columbus module. The Japanese Experiment Module - Exposed Facility is attached to the exterior of the Japanese Experiment Module. The EXPRESS Logistics Carrier (ELC) is a pallet designed to support external research hardware and store external spares (called Orbital Replacement Units) needed over the life of the ISS. Currently, four ELCs are mounted to ISS trusses, providing

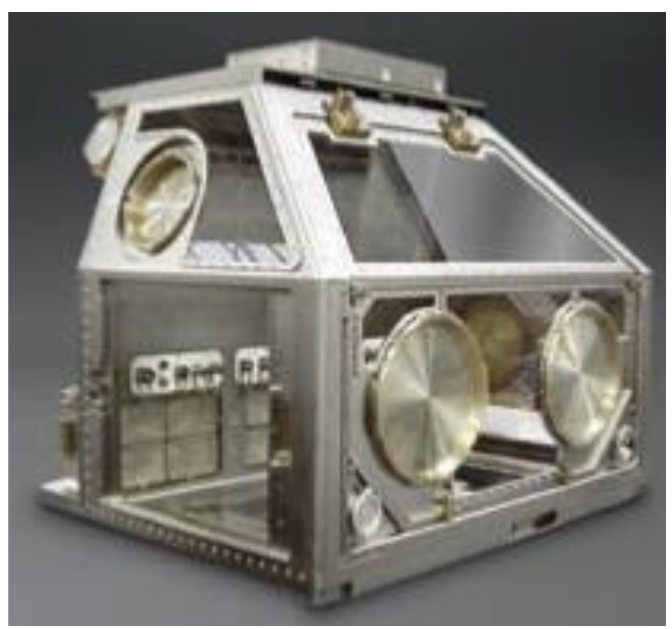

Figure 2. The LSG

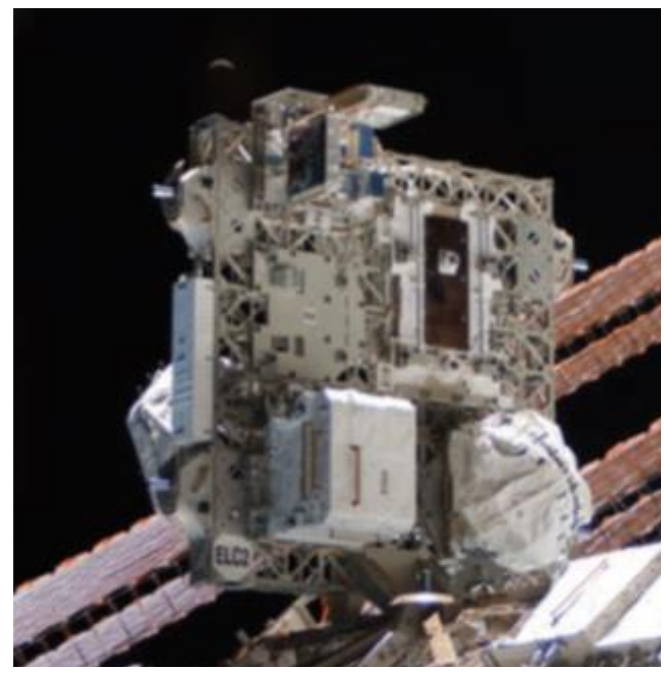

Figure 3. ISS ELC2

unique vantage points for space, technology and Earth observation investigations.

\section{ISS REQUIREMENTS}

ISS electromagnetic interference (EMI) and electromagnetic compatibility (EMC) requirements are contained in a number of ISS requirements documents. SSP 30243, Space Station Requirements for Electromagnetic Compatibility, contain the system-level EMC requirements. It is a tailored version of MIL-E-6051D, Electromagnetic Compatibility Requirements, Systems. Electrical bonding requirements are in SSP 30245, Space Station Electrical Bonding Requirements, which is a tailored version of MIL-B-5087B, Bonding, Electrical, and Lightning Protection, for Aerospace Systems. SSP 30237, Space Station Electromagnetic Emission and Susceptibility Requirements, and SSP 30238, Space Station Electromagnetic Techniques, are derived versions of MIL-STD-461B, Electromagnetic Emissions and Susceptibility Requirements for the Control of Electromagnetic Interference, and MIL-STD-462, 
Electromagnetic Emissions and Susceptibility, Test Methods for, respectively. SSP 30242, Space Station Cable/Wire Design and Control Requirements for Electromagnetic Compatibility, while very similar to DOD-W-83575, Wiring Harness, Space Vehicle, Design and Testing, General Specification for, is in fact a unique document for ISS. Its purpose is to provide a uniform specification and methodology for cabling and wiring to minimize field-towire coupling and crosstalk. Finally, SSP 30240, Space Station Grounding Requirements, contains electrical grounding and isolation requirements. The vehicle uses dedicated returns for signals and power. The vehicle also uses a distributed single ground reference system, or single point ground, for the referencing power and signals in order to minimize interference as well as interactions with the natural geomagnetic and plasma environment and maximize crew safety.

TABLE I. SPECIFICATIONS CITED

\begin{tabular}{|c|c|c|}
\hline Document Number & Document Title & Notes \\
\hline SSP 30243 & $\begin{array}{lr}\text { Space } & \text { Station } \\
\text { Requirements } & \text { for } \\
\text { Electromagnetic } & \\
\text { Compatibility } & \\
\end{array}$ & $\begin{array}{l}\text { MIL-E-6051D, } \\
\text { tailored for ISS }\end{array}$ \\
\hline MIL-E-6051D & $\begin{array}{l}\text { Electromagnetic } \\
\text { Compatibility } \\
\text { Requirements, Systems }\end{array}$ & \\
\hline SSP 30245 & $\begin{array}{l}\text { Space Station Electrical } \\
\text { Bonding Requirements }\end{array}$ & $\begin{array}{l}\text { MIL-B-5087B, } \\
\text { tailored for ISS }\end{array}$ \\
\hline MIL-B-5087B & $\begin{array}{l}\text { Bonding, Electrical, and } \\
\text { Lightning Protection, for } \\
\text { Aerospace Systems }\end{array}$ & \\
\hline SSP 30237 & $\begin{array}{ll}\text { Space } & \text { Station } \\
\text { Electromagnetic } & \\
\text { Emission } & \text { and } \\
\text { Susceptibility } & \\
\text { Requirements } & \\
\end{array}$ & $\begin{array}{l}\text { Derived from } \\
\text { MIL-STD-461B }\end{array}$ \\
\hline MIL-STD-461B & $\begin{array}{l}\text { Electromagnetic } \\
\text { Emissions and } \\
\text { Susceptibility } \\
\text { Requirements for the } \\
\text { Control of } \\
\text { Electromagnetic } \\
\text { Interference }\end{array}$ & \\
\hline SSP 30238 & $\begin{array}{l}\text { Space Station } \\
\text { Electromagnetic } \\
\text { Techniques }\end{array}$ & $\begin{array}{l}\text { Derived from } \\
\text { MIL-STD-462 }\end{array}$ \\
\hline MIL-STD-462 & $\begin{array}{lr}\text { Electromagnetic } & \\
\text { Emissions } & \text { and } \\
\text { Susceptibility, } & \text { Test } \\
\text { Methods for, } & \\
\end{array}$ & \\
\hline SSP 30242 & $\begin{array}{l}\text { Space } r \text { Station } \\
\text { Cable/Wire Design and } \\
\text { Control Requirements } \\
\text { for Electromagnetic } \\
\text { Compatibility }\end{array}$ & $\begin{array}{c}\text { Unique ISS } \\
\text { document similar } \\
\text { to, but not derived } \\
\text { from DOD-W- } \\
83575\end{array}$ \\
\hline DOD-W-83575 & $\begin{array}{l}\text { Wiring Harness, Space } \\
\text { Vehicle, Design and } \\
\text { Testing, General } \\
\text { Specification for, }\end{array}$ & \\
\hline SSP 30240 & $\begin{array}{ll}\text { Space } & \text { Station } \\
\text { Grounding } & \\
\text { Requirements } & \\
\end{array}$ & $\begin{array}{l}\text { Grounding } \\
\text { requirements } \\
\text { unique to ISS }\end{array}$ \\
\hline
\end{tabular}

\section{Payload Requirements}

SSP 57000, Pressurized Payloads Interface Requirements Document, and SSP 57003, Attached Payload Interface Requirements Document, provide the payload developer with the interface design requirements to ensure the safety of the ISS crew, the ISS vehicles, as well as transport vehicles and neighboring payloads. These documents contain EMC requirements derived from the previously mentioned EMI and EMC requirements documents or direct the reader to unique sections of those documents. These requirements address radiated and conducted emissions and susceptibility, electrical isolation, electrical grounding, electrical bonding, shielding, cable/wire treatment for EMC, as well as other requirements needed to ensure the payload achieves EMC with the ISS vehicle, other payloads, transportation vehicles, and does not jeopardize the health and safety of the crew.

\section{DESIGN CONSIDERATIONS}

Translating these EMC requirements into a practical, compliant design may seem baffling to some designers. What follows is some practical information to guide the payload developer in selecting and implementing design solutions that are compliant with ISS EMI and EMC requirements.

\section{Power Filter Design}

Control of power line conducted emissions protects power quality, limits electric field radiation, and controls noise currents on vehicle structure. Because ISS does not use the radio frequency (RF) spectrum below $100 \mathrm{MHz}$, ISS does not impose radiated emissions limits on payloads below that frequency. ISS also imposes cable separation requirements to limit crosstalk, thus controlling conducted emissions to limit electric field radiation is of lesser importance. ISS CE01, low frequency, and CE03, high frequency conducted emissions limits are to prevent electrical loads from generating ripple voltages greater than those generated by the power source and distribution system. The ISS conducted emissions test methods use the 10-microfarad feed-through capacitors as part of the standard test setup, based on that found in MILSTD-462. Starting with Revision D of MIL-STD-462, the test setup uses Line Impedance Stabilization Networks (LISNs) as the power source impedance. These LISNs contain 50 microhenry $(\mu \mathrm{H})$ inductors, thus the power source

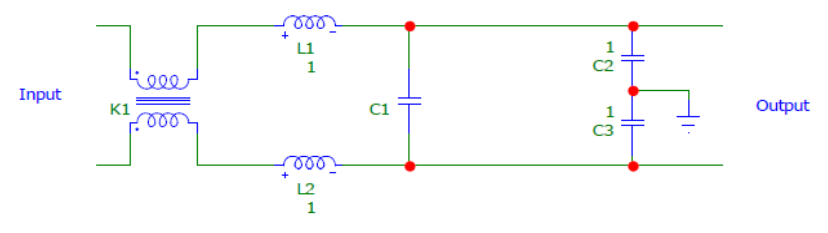

Figure 4. 461B Filter 


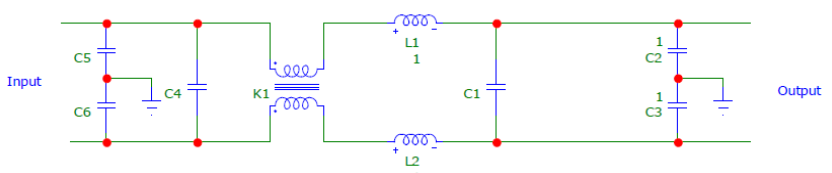

Figure 5. 461D Filter

impedance can be quite high even at low frequencies. However, the LISN impedance is not representative of any ISS power source impedances. MIL-STD-461F discussed the substitution of the $5 \mu \mathrm{H}$ LISN in lieu of the $50 \mu \mathrm{H}$ LISN for testing, however, even this lower source impedance may exceed that of most payload facilities. As stated in [5], maximizing EMI power filter attenuation is a matter of providing a mismatch between source and load impedances. As such, looking from the source into the filter, the first element in the filter should be a high impedance (inductor), assuming a low source impedance, or a low impedance (capacitor) assuming a high source impedance. Figures 4 and 5 show simplified schematics of EMI power filters from two different manufacturers (Note: the authors simplified the schematics to protect proprietary information, but the circuit

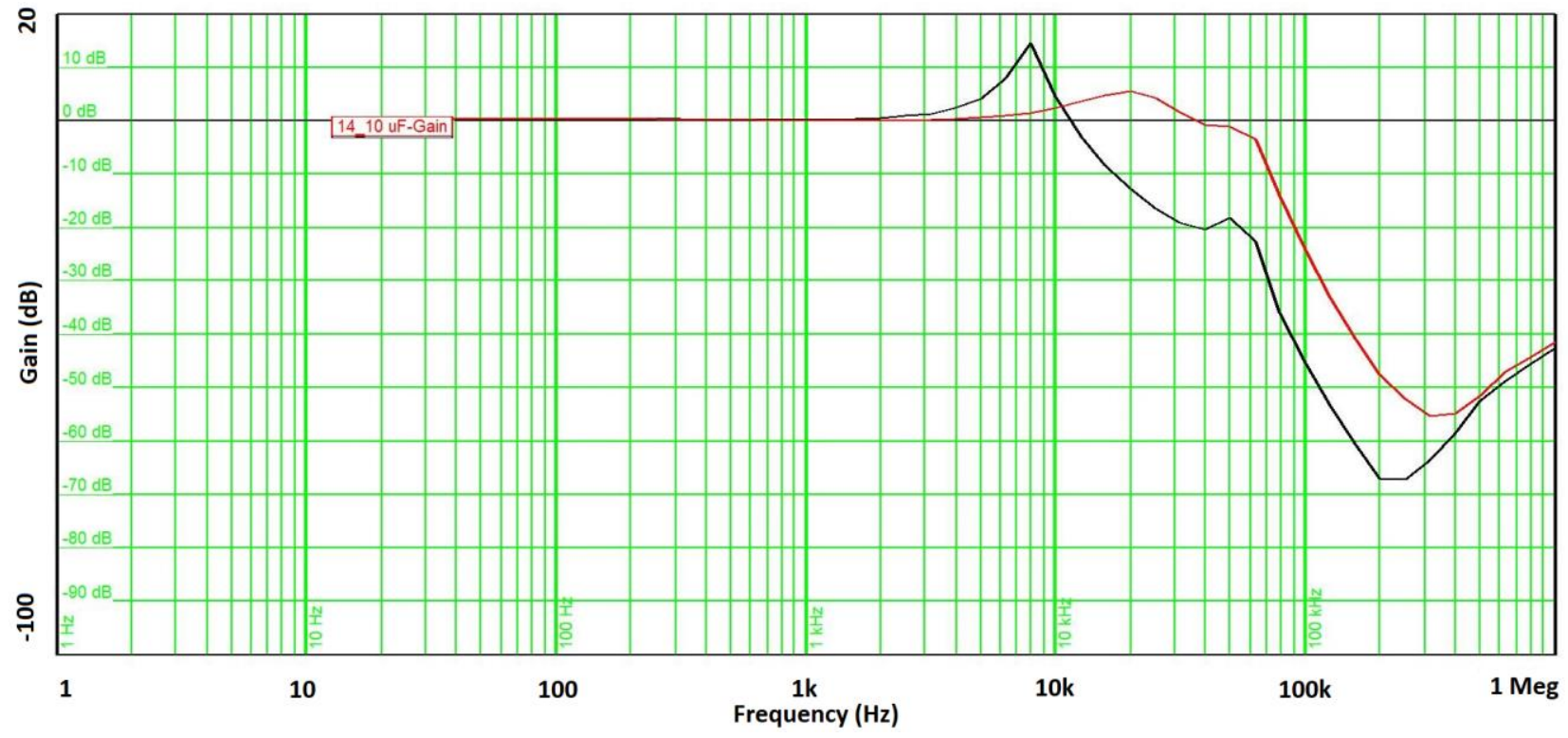

Figure 6. 461B Filter Performance

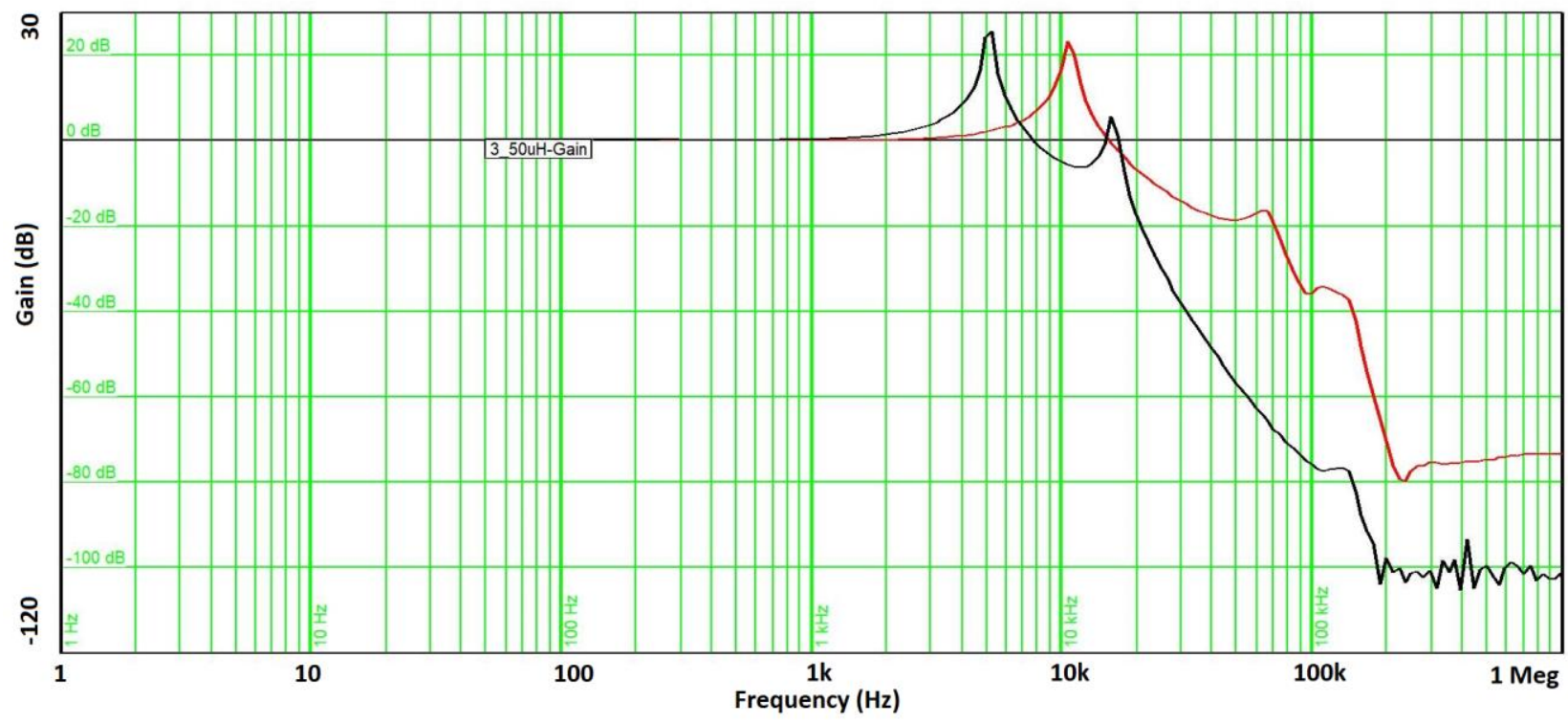

Figure 7. 461D Filter Performance 
diagrams provide the basic design elements). Both manufacturers advertise the filter complies with MIL-STD461. However, the manufacturer designed the filter shown in Figure 4 prior to the publication of MIL-STD-461D, when the test source impedance was still the $10 \mu \mathrm{F}$ feed-through capacitors. The filter design shown in Figure 5 came after, where the source impedance is two $50 \mu \mathrm{H}$ LISNs. Note the design in Figure 4, referred to hereafter as "461B filter", has both a common mode inductor (K1) and differential mode inductors (L1 \& L2) as its first elements, to provide mismatch with the low source impedance. On the other hand, the design in Figure 5, referred to hereafter as "461D filter" has both Y (line-to-ground) capacitors (C5 and C6) and an X (line-toline) capacitor $(\mathrm{C} 4)$ as its first elements, providing a mismatch with the high source impedance. Figure 6 shows the comparison of filter performance of the 461B filter with a $50 \mu \mathrm{H}$ LISN source impedance versus a $10 \mu \mathrm{F}$ feed-through capacitor source impedance. Figure 7 is the same comparison of performance for the 461D filter. In both plots, the red trace is the performance with $10 \mu \mathrm{F}$ feed-through capacitors and the black trace is with the $50 \mu \mathrm{H}$ LISNs. The difference in performance of the $461 \mathrm{~B}$ filter is $\sim 15 \mathrm{~dB}$ at $100 \mathrm{kHz}$ but is negligible above $500 \mathrm{kHz}$. However, the 461D filter performance differs by $20 \mathrm{~dB}$ or more above $30 \mathrm{kHz}$. While it is tempting to compare the absolute filter performance of the two, the reader should note the 461B filter is 1/10th the weight and volume of the $461 \mathrm{D}$ filter and this data merely shows differences in performance based on source impedance.

\section{Power Supply Selection}

When constructing a power budget for a payload, developers need to consider the actual power supply that will connect to ISS power. A dc-dc converter is rated for output power in watts to size the internal components appropriately. Typically, variations of two types of converters are available to payload developers, pulse width modulated (PWM) converters and resonant frequency converters. A PWM converter will change the duty cycle of its switching frequency in response to the power demand on the output. While the fundamental switching frequency of the converter does not change, the conducted emissions spectrum above this frequency will change. The higher the power demand, the greater the frequency content. Resonant frequency converters, on the other hand, change the fundamental switching frequency in response to the output power demand. Depending on the loading of the converter, the differential conducted emissions profile changes. Figure 8 shows the

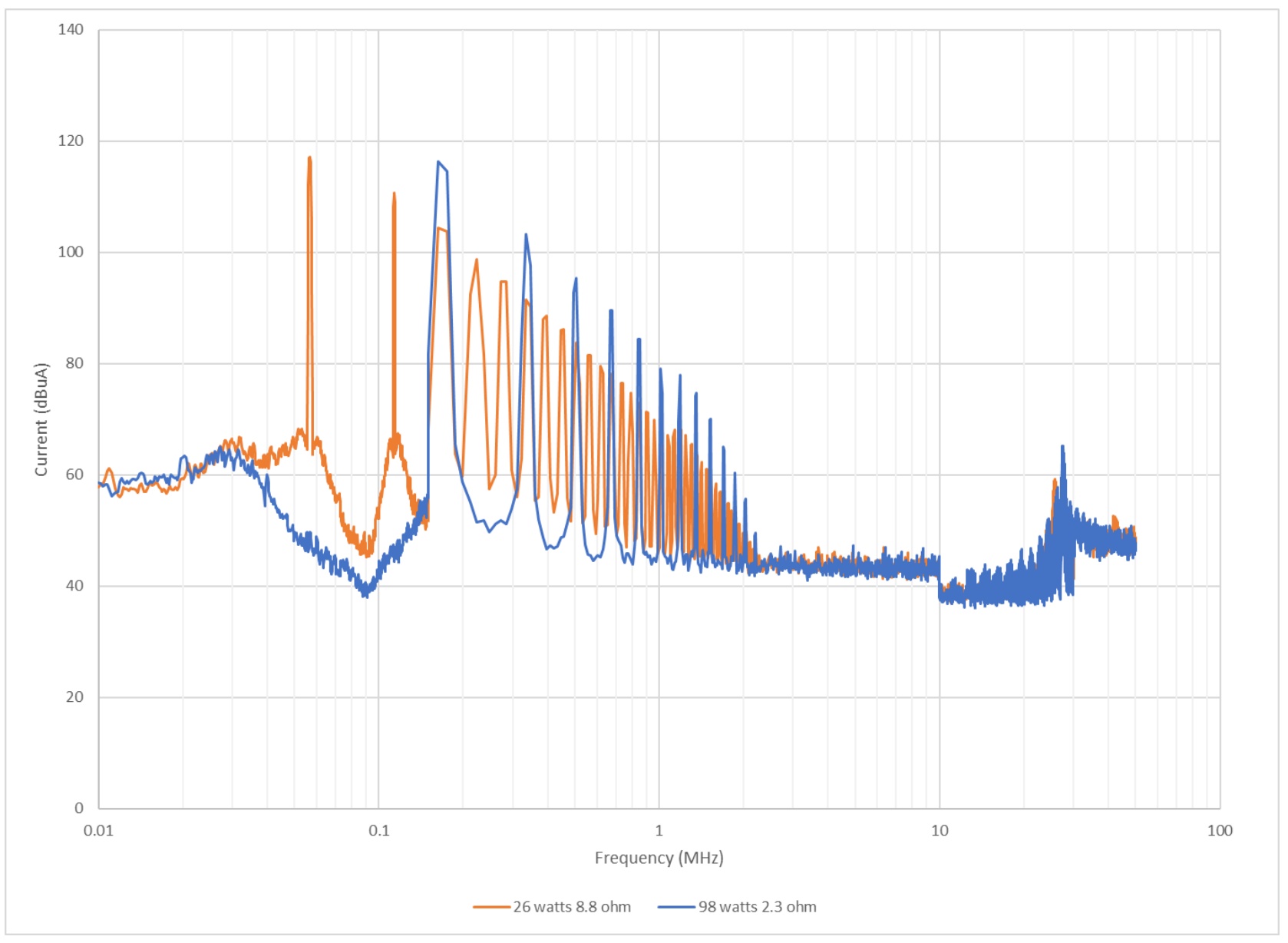

Figure 8. CE03 High Frequency Conducted Emissions Plot of a dc-dc Converter with different loads attached 
high frequency conducted emissions of a $28 \mathrm{~V}$ to $15 \mathrm{~V}$ dc-dc converter, rated for 100 watts output attached to different resistive loads. The resultant power output of the converter was 26 watts and 98 watts. The conducted emissions profile is different depending on the loading of the converter, and the developer should keep these differences in mind when designing a filter. Due to the significant shift in switching frequency, some manufacturers provide filters matched for certain converter load profiles. If the converter operates outside this range, the filter no longer provides the necessary attenuation to meet conducted emissions limits. When planning EMI tests, the payload developer should be cognizant of the impact of loading conditions to ensure the worst case operational profile is tested.

\section{GROUNDING/ISOLATION}

Payload users of 120 VDC or 28 VDC power must have power inputs that are dc isolated from chassis by a minimum of 1 megohm. It should also be isolated from equipment conditioned power return/reference and signal returns. This ensures that electrical current does not intentionally return on vehicle structure and follows the single point ground methodology (single reference). The single point ground/single reference scheme as seen in Figure 9, is a derivative of a single point star ground (as used in industrial applications) in which each isolated power and signal domain is referenced once to the ground plane (spacecraft structure). Using a single reference scheme reduces noise voltages caused by noise currents flowing through structure and provides a path for fault current to return to its source.

For payloads that utilize AC power, supplied by the ISS AC Inverter, each supply line must return current on a neutral wire routed with the supply line and the neutral wire shall be isolated from chassis at the load. Not only does this prevent $60 \mathrm{~Hz}$ noise from appearing on ISS structure, it serves to provide another layer of protection against crew electrical shock.

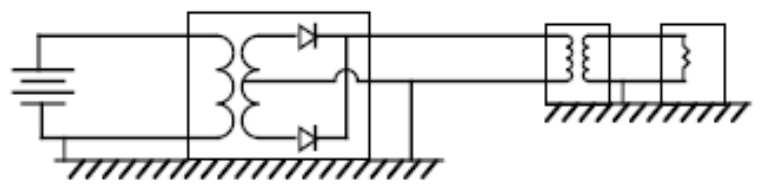

\section{Figure 9. Example of single reference/single point ground}

For input/output connections to a payload, differential analog circuits must employ a separate return, and low-level discrete signals are required to use individual returns. The use of dedicated returns minimizes loop areas that could source radiated emissions, leading to EMI non-compliances and interference with other payloads.

The input/output connections requirements can prove to be difficult for payload to developers that utilize single-board microcontrollers such as an Arduino ${ }^{\circledR}$ or Raspberry PI® because these devices reference native analog and digital return to the board common. This board common connects to the input power common. Utilizing an isolating $\mathrm{dc}-\mathrm{dc}$ converter for input power or configuring the inputs to differential inputs are a couple of solutions for this issue.

Universal Serial Bus (USB), Ethernet, and other input/output interface circuits can be a source of single point ground violations. Many integrated circuit data sheets, application notes, and design guides provide simplified circuit schematics with "ground" connections. In most cases, it is not obvious whether this "ground" is signal ground, chassis ground, or both. Some design recommendations include capacitors or inductors in the schematic to provide isolation or prevent the flow of noise currents. However, many provide little guidance concerning circuit referencing or isolation. Improper circuit referencing can lead to transceiver noise issues, which affect data communications. It can also lead to radiated emissions issues that may require hardware redesign.

\section{SHIELDING}

Shielding effectiveness is a function of the reflectance or absorption of electromagnetic fields. Reflectance is the primary method to attenuate electric fields. Metal is the preferred material to use, although commercial applications have used conductive plastics with high electrical conductivity successfully. Absorption is the primary method to attenuate magnetic fields. Absorption correlates with the permeability, conductivity, thickness of the shield and the frequency of the incident field. Highly permeability materials such as steel or Mu-metal ${ }^{\circledR}$ can provide magnetic field shielding. However, such materials tend to be heavy and costly, so alternatively the hardware developer should control magnetic fields by limiting cable loop areas and magnetic flux leakage to minimize cost and weight impacts.

The most common types of cable shields used are braid, flexible conduit, and rigid conduit. Braid is the most common method for shielding of spaceflight cabling. The cable shield should act as an extension of the payload's faraday cage, that is, the cable shield is an extension of the shielded enclosure. The shield termination is just as important the shield material. A "pigtail" or direct wire shield termination is ineffective above a few megahertz because of the high impedance of the termination. Thus, the poor termination negates the benefits of the shielding. Therefore, cable shields should have a peripheral or $360^{\circ}$ termination.

Cable shields routed outside the payload enclosure are required to have shield terminations at both ends of the cables. There is a common misconception that this dual shield termination leads to ground loops. A ground loop occurs only if the shield connects to the internal signal or power ground or the payload does not comply with the single point reference isolation requirements. The misconception stems from the commercial instrumentation and control industry, where single point ground methodology for 
equipment conflicts with the methodology used in human space flight.

\section{DATA BUS CONSIDERATIONS}

ISS provides payloads with different data communications options. Payloads have the option of using: USB, RS 232, RS 422, RS 485, high rate fiber optic, MIL-STD-1553, or Ethernet (10/100/1000 Mbps), depending on payload location and payload facility capabilities.

RS 232 is a single ended communications data bus. That is, the signal is referenced to a common ground, which violates the ISS single point ground concept without some sort of ground loop isolation. The RS 232 signal can be easily corrupted and a source of radiated noise. Proper shielding and shield termination of RS 232 cables is required for compliance with radiated emissions limits. Many commercially available RS 232 cables have poorly terminated shields, resulting in radiated emissions noncompliances. For these reasons, the payload developer should avoid RS 232 use.

RS 422 and RS 485 are balanced, differential communications data buses. Isolated RS 422 and RS 485 transceivers meet ISS grounding/isolation requirements and have better noise immunity than RS 232. Non-isolated transceivers can lead to ground loops and noise issues even with external isolation solutions. As with RS 232, route RS 422 and RS 485 signals in properly shielded cabling.

USB is another balanced, differential communications data bus. Isolated USB 2.0 and 3.0 transceivers are available commercially and these devices comply with ISS grounding/isolation requirements. When combined with properly shielded cables, these data buses can exhibit both low radiated emissions and high radiated immunity levels.

Ethernet is also a balanced differential communications data bus. Like USB, isolated transceivers are commercially available that provide appropriate isolation. Unlike USB, Ethernet specifications do not require a shielded cable. While it is possible to comply with radiated emissions using unshielded cables, the designer should use shielded cables to minimize emissions and avoid potential non-compliances.

\section{BONDING}

Electrical bonding is the process of providing an electrical connection across faying surface mechanical interfaces to minimize electrical potential differences between individual parts of the connecting structure. Bonding requirements for payloads are derived from SSP 57000 and SSP 57003, which references NASA-STD-4003. In the guidance documents, three different bond classes are specified representing different scenarios for a required bond. They are Class $\mathrm{H}$ (shock hazard), Class R, (radio frequency), and Class $\mathrm{S}$ (electrostatic charge). A simplified description of the three types of bonds are in Table II.
Any payload that receives power from ISS will need to comply with the Class $\mathrm{H}$ bonding requirements to provide a fault current return path back to the source to prevent shock hazards, to clear electrical faults, and prevent other hazardous overheating/overcurrent conditions.

While it appears to be more stringent, due to the lower bond resistance, a Class $\mathrm{R}$ bond is not a substitute for a Class $\mathrm{H}$ bond. The intent of a Class $\mathrm{R}$ is to provide a low impedance path so that noise currents do not generate excessive noise voltages. These noise currents could be as much as a few hundred milliamperes of current while fault currents could be 50 amperes or greater. Thus, a class $\mathrm{H}$ bond design must

TABLE II. SIMPLIFIED DESCRIPTION OF BOND CLASSES

\begin{tabular}{|c|c|c|c|}
\hline Bond Class & $\begin{array}{l}\text { Class H } \\
\text { (Shock } \\
\text { Hazard) }\end{array}$ & $\begin{array}{c}\text { Class R } \\
\text { (Radio } \\
\text { Frequency) }\end{array}$ & $\begin{array}{c}\text { Class S } \\
\text { (Electrostatic } \\
\text { Charge) }\end{array}$ \\
\hline $\begin{array}{l}\text { Purpose of } \\
\text { bond }\end{array}$ & $\begin{array}{l}\text { Protects } \\
\text { against fire } \\
\text { or shock to } \\
\text { personnel. }\end{array}$ & $\begin{array}{c}\text { Protects } \\
\text { equipment } \\
\text { from RF } \\
\text { emissions. } \\
\text { Includes } \\
\text { antenna } \\
\text { mounts and } \\
\text { cable shield } \\
\text { connections. }\end{array}$ & $\begin{array}{c}\text { Protects again } \\
\text { electrostatic } \\
\text { discharge }\end{array}$ \\
\hline $\begin{array}{c}\text { DC } \\
\text { resistance } \\
\text { bond } \\
\text { requirement }\end{array}$ & $\begin{array}{l}\text { Bonding } \\
\text { resistance } \\
\text { requirements, } \\
0.1 \text { ohm or } \\
\text { less. }\end{array}$ & $\begin{array}{c}\text { Bonding } \\
\text { resistance } \\
\text { requirement, } \\
2.5 \\
\text { milliohms or } \\
\text { less. Low } \\
\text { inductance } \\
\text { required. }\end{array}$ & $\begin{array}{l}\text { Bonding } \\
\text { resistance } \\
\text { requirement, } 1 \\
\text { ohm or less. }\end{array}$ \\
\hline
\end{tabular}

handle the maximum fault current without failure; this would require a contact area much greater than that for a class $\mathrm{R}$ bond.

The purpose of the class $\mathrm{R}$ bond is oftentimes confusing to payload developers. Most believe their hardware does not generate RF emissions, thus class R would not be applicable. However, a dc-dc converter switching at $100 \mathrm{kHz}$ or a microprocessor with a $16 \mathrm{MHz}$ clock signal will generate RF emissions. The performance of a common mode filter to meet conducted emissions or the shielding effectiveness of a payload enclosure with a lid will be dependent whether a low impedance path exists to minimize noise voltage generation. If the lid to enclosure interface does not provide a Class $\mathrm{R}$ bond, this will become an antenna. This antenna will radiate noise and jeopardize chances of complying with radiated emissions limits. If the USB connector shell does not make full positive contact around its periphery, the noise internal to the payload will radiate from the aperture and/or appear as noise currents on the shield, leading to radiated emissions non-compliances. Maintaining shielding effectiveness of payload enclosures requires good electrical bonds at seams, 
joints, connector mounting locations, and other enclosure discontinuities. The key to making good electrical bonds is having appropriate design rigor as well as proper materials selection and manufacturing processes.

Class S bonds prevent electrostatic charge build up by allowing the charge to dissipate. External payloads will require Class $\mathrm{S}$ bonds to ensure that plasma charge build up does not create hazards for extravehicular activities or generate discharges that could interfere with communications or other operations.

\section{Safety Considerations}

Payloads, which contain safety critical circuits, require additional considerations. A safety critical circuitry is circuitry controlling catastrophic or critical hazards to crew or vehicle. When the failure or improper performance of circuitry can cause harm to vehicle or crew, the payload must undergo EMI susceptibility testing. These test levels are quite stringent, so the payload developer should be cautious about using electrical and electronic circuitry to control hazards.

Portable payloads or payloads that do not use faying surface (meta-to-metal) bonding for Class $\mathrm{H}$ bonds must have independent, redundant electrical bond paths for fault current return and shock hazard prevention. While some payload facilities provide redundant bonding provisions, others do not so the payload developer should be aware the payload location might drive the design.

\section{SUMMARY}

The ISS provides payload developers with unique research opportunities. However, the payload developer must incorporate special EMC considerations to be compatible with the ISS and other payloads. The developer must understand COTS equipment and components used in payload designs to ensure that these items do not create EMI issues or compromise payload performance. The payload developer can contact the ISS Research Integration Office for more information and design guidance in developing electromagnetically compatible payloads for the ISS.

\section{REFERENCES}

[1] "Reference Guide to the International Space Station," NASA ISS Program Office, Houston TX, USA, NP-201505-022-JSC, 2015.

[2] "International Space Station Facilities: Research in Space 2017 and Beyond," NASA ISS Program Science Office, Houston, TX, USA, NP-2017-04-014-B-JSC, 2017.

[3] "White Paper in Support of SSP 30237 Development," The Boeing Company, Houston, TX, USA, D683-29775, Jan. 1992.

[4] T.L. Clark, M.B. McCollum, D.H. Trout, K. Javor, "Marshall Space Flight Center Electromagnetic Compatibility Design and Interference Control (MEDIC) Handbook - CDDF Final Report, Project No. 93-15," NASA Marshall Space Flight Center, Huntsville AL, USA, NASA Reference Publication 1368, June 1995.

[5] M.J. Nave, Power Line Filter Design for Switched-Mode Power Supplies, New York, NY, USA, Van Nostrand Reinhold, 1991.

[6] Electrical Bonding for NASA Launch Vehicles, Spacecraft, Payloads, and Flight Equipment, NASA-STD-4003A, 2013.

[7] Pressurized Payloads Interface Requirements Document, SSP 57000, Revision S, 2018.

[8] Payload Safety Policy and Requirements for the International Space Station, SSP 51700, 2010. 


\section{BIOGRAPHY}

Matthew McCollum received a B.S. in Applied Physics from Auburn University in 1990. He has been with NASA's Marshall Space Flight Center for 28 years. He has been the Electromagnetic Effects lead for the ISS Program Office since 1997. He has been involved in development of numerous crewed and un-crewed spacecraft and payloads, serving in EMC design and EMI testing capacities. An IEEE Senior Member and member of the IEEE EMC Society, he started his career with Grumman Aircraft, now Northrup Grumman, on the Space Station Freedom Program.

Larry Kim received a B.S in Electrical Engineering from University of Alabama in Huntsville in 1990, a M.S. in Electrical Engineering from University of Alabama in Birmingham in 2001. He has been with NASA's Marshall Space Flight Center for more than 15 years working on electrical system integration and electromagnetic compatibility for ISS payloads. He has more than 10 years of experience designing payload electronics in medical research program for Space Shuttle SPACEHAB and ISS Program prior to joining NASA's Marshall Space Flight Center.

Christopher Lowe, PE, currently works as an Electrical Engineer for the NASA Marshall Space Flight Center Electromagnetic Environmental Effects group through the Jacobs Space Exploration Group partner, Aerodyne Industries. Previously, he worked for a small nuclear engineering consulting firm in Knoxville, Tennessee. While at this firm, he tested and completed diagnostic work for instrumentation and control systems in commercial nuclear power plants. This also dealt with the electromagnetic compatibility of newer digital upgrades in a noisy analog environment. Chris received his Bachelor of Science Degree in Electrical Engineering from The University of Tennessee in 2010. He also holds his Professional Engineering License through the State of Tennessee. 